\title{
IMPLEMENTASI PROGRAM KARTU INDONESIA SEHAT DALAM MENINGKATKAN KUALITAS PELAYANAN KESEHATAN DI RUMAH SAKIT UMUM DAERAH KABUPATEN BOVEN DIGOEL PROVINSI PAPUA
}

\author{
Primus Yaluwo*); Bambang Supriyadi; Andi Pitono \\ Pascasarjana Institut Pemerintahan Dalam Negeri Jakarta \\ *email:primuswaluyo21@gmail.com
}

\begin{tabular}{r|} 
Paper Accepted: 26 Juni 2021 \\
Paper Reviewed: 27-30 Juni 2021 \\
Paper Edited: 01-06 Juli 2021 \\
Paper Approved: 08 Juli 2021
\end{tabular}

\begin{abstract}
ABSTRAK
Penelitian ini bertujuan untuk mengetahui implementasi kebijakan program Kartu Indonesia Sehat di Rumah Sakit Umum Daerah Kabupaten Boven Digoel Provinsi Papua. Penelitian ini menggunakan metode deskriptif dengan pendekatan induktif. Hasil penelitian menunjukkan beberapa hal. Pertama, dengan menggunakan analisis kebijakan model Merille S. Grindle ditemukan fakta tidak adanya kepentingan lain dari para pelaksana program Kartu Indonesia Sehat (KIS). Pegawai Rumah Sakit seperti dokter hanya melaksanakan tugasnya untuk keberhasilan program ini. Kemudian Pegawai Rumah Sakit sebagai pelaksana program tidak memperoleh manfaat apapun, mereka hanya sebagai implementor dari program ini. Berikutnya, Pegawai Rumah Sakit sebagai pelaksana program menginginkan peserta KIS merasa puas atas pelayanan yang mereka terima serta lebih memahami bagaimana pola hidup sehat agar tidak mudah sakit. Faktor pendukung implementasi program KIS adalah tersedianya sumber daya manusia atau tenaga medis yang cukup baik. Sementara faktor penghambatnya antara lain; masih minimnya sarana dan prasana di Rumah Sakit; masih minimnya pos anggaran sehingga program KIS belum disosialisaikan dengan baik. Diperlukan perumusan program dan strategi yang mencakup; pemanfaatan teknologi informasi dan iklan dalam memperkenalkan program KIS; meningkatkan sarana dan prasarana; serta perlunya pola kerjasama yang baik antara Pemerintah Daerah, Dinas kesehatan, dan Rumah Sakit Umum Daerah Kabupaten Boven Digoel dalam memperkenalkan Program KIS.
\end{abstract}

Kata Kunci : Implementasi, Kebijakan Program, Kartu Indonesia Sehat

\section{PENDAHULUAN}

\section{Latar Belakang}

Dalam upaya mencapai derajat kesehatan masyarakat setinggi-tingginya, maka dari itu pemerintah menyelenggarakan Program Jaminan Kesehatan Nasional-Kartu Indonesia Sehat (JKN-KIS). Implementasi Jaminan Kesehatan Nasional mulai dijalankan 1 Januari 2014 sesuai amanat Peraturan Presiden Nomor 12 Tahun 2013 tentang Jaminan Kesehatan. Tujuan utama
Program Jaminan Kesehatan Nasional (JKN) untuk memberikan perlindungan kesehatan dalam bentuk manfaat pemeliharaan kesehatan dalam rangka memenuhi kebutuhan dasar kesehatan yang diberikan kepada setiap orang yang telah membayar iuran atau iurannya dibayar oleh pemerintah (Kemenkes RI, 2014). Program Jaminan Kesehatan Nasional ini diselenggarakan melalui mekanisme asuransi sosial yang bertujuan agar seluruh penduduk Indonesia terlindungi dalam sistem asuransi sehingga mereka dapat memenuhi kebutuhan dasar 
kesehatan.

Pemerintah membagi jenis kepesertaan (JKN-KIS) menjadi dua jenis berdasarkan sumber pembiayaan iuran, yaitu: Peserta Penerima Bantuan Iur (PBI) berdasarkan Perpres Nomor 101 Tahun 2011 dan Non Penerima Bantuan Iur (Non-PBI) berdasarkan Perpres Nomor 12 Tahun 2013. Peserta (PBI) Jaminan Kesehatan meliputi orang yang tergolong fakir miskin dan orang tidak mampu, sedangkan Peserta bukan (PBI) Jaminan Kesehatan sebagaimana yang dimaksud merupakan peserta yang tidak tergolong fakir miskin dan orang tidak mampu yang terdiri atas:

1. Pekerja Penerima Upah dan anggota keluarganya

2. Pekerja Bukan Penerima Upah dan anggota keluarganya

3. Bukan Pekerja dan anggota keluarganya

Hadirnya program (JKN-KIS) di tengahtengah masyarakat merupakan wujud hadirnya negara atas kepeduliannya terhadap kesehatan masyarakat. Selain itu, adanya kebijakan dengan mengimplementasikan program Kartu Indonesia Sehat juga berperan untuk meningkatkan kualitas pelayanan kesehatan pada rumah sakit yang ada di Indonesia khususnya di Rumah Sakit Umum Daerah Kabupaten Boven Digoel Provinsi Papua. Dalam permasalahan yang ada di Rumah Sakit Umum Daerah Kabupaten Boven Digoel berdasarkan informasi sementara penerapan Program Kartu Indonesia Sehat (KIS) masih belum dapat berjalan maksimal seperti masih kurang efektif dan efisien rumah sakit dalam memberikan pelayanan, rendahnya pengetahuan peserta program (KIS) juga menjadi salah satu faktor penerapan belum berjalan maksimal, serta fasilitas yang kurang maksimal dalam rumah sakit menjadikan terhambatnya rumah sakit untuk meningkatkan kualitas pelayanan kesehatan pada masyarakat.

Pasien pengguna Kartu Papua Sehat (KPS) maupun BPJS Kesehatan kerap dihimbau untuk membawa surat rujukan jika berobat ke rumah sakit. Jika tidak, maka klaim pembiayaan tak bisa diajukan. Namun, himbauan ini jadi sebatas kata-kata. "Jika tidak dilayani, warga yang marah. Kami sudah sering mengedukasikan hal ini, tapi ya selalu saja berulang. Tidak mungkin juga kami suruh balik. Jadinya, kami tetap melayani dengan kepesertaan (KPS). Kalau sudah begini kami tidak bisa mengklaim ke BPJS Kesehatan, tapi ke Pemda yang tarif kapitasinya lebih kecil," tutur salah satu pimpinan Rumah Sakit Umum Daerah Boven Digoel dr. Carolina, didampingi dr. Melly. Keluhan itu ia sampaikan saat Tim Monitoring Program Jaminan Sosial Dewan Jaminan Sosial Nasional (DJSN) DR. Taufik Hidayat, M. Ec, Subiyanto, SH, dr. Asih Eka Putri, MPPM, dr. Zainal Abidin, MH, dan Rudy Prayitno, SE, berkunjung ke Rumah Sakit Umum Daerah Boven Digoel, Papua, Rabu (13/4/2016).

\section{Perumusan Masalah}

Berdasarkan perumusan masalah yang telah diuraikan, maka pembahsan masalah dalam penelitian ini adalah sebagai berikut:

1. Bagaimana Implementasi Program Kartu Indonesia Sehat Dalam Meningkatkan Kualitas Pelayanan Kesehatan di Rumah Sakit Umum Daerah Kabupaten Boven Digoel Provinsi Papua selama ini?

2. Apa saja faktor pendukung dan faktor penghambat Implementasi program Kartu Indonesia Sehat Dalam Meningkatkan Kualitas Pelayanan Kesehatan di Rumah Sakit Umum Daerah Kabupaten Boven Digoel Provinsi Papua?

3. Strategi apa saja yang harus perlu dapat dilakukan guna untuk mengatasi hambatan-hambatan Implementasi Progran Kartu Indonesia Sehat Dalam Meningkatkan Kualitas Pelayanan Kesehatan di Rumah Sakit Umum Daerah Kabupaten Boven Digoel Provinsi Papua?

\section{Maksud dan Tujuan Penelitian}

Adapun tujuan penelitian ini dilakukan yaitu bertujuan untuk menganalisis:

1. Bagaimana Implementasi Program Kartu Indonesia Sehat Dalam Meningkatkan Kualitas Pelayanan Kesehatan di Rumah Sakit Umum Daerah Kabupaten Boven Digoel Provinsi Papua selama ini.

2. Apa saja faktor pendukung dan faktor penghambat Implementasi 
Program Kartu Indonesia Sehat Dalam Meningkatkan Kualitas Pelayanan Kesehatan di Rumah Sakit Umum Daerah Kabupaten Boven Digoel Provinsi Papua.

3. Strategi apa saja yang harus perlu dapat dilakukan guna mengatasi hambatan-hambatan Implementasi Program Kartu Indonesia Sehat Dalam Meningkatkan Kualitas Pelayanan Kesehatan di Rumah Sakit Umum Daerah Kabupaten Boven Digoel Provinsi Papua.

\section{Gambaran Umum Lokasi dan Institusi Penelitian}

\section{Lokasi Penelitian}

Penelitian ini dilaksanakan di Kabupaten Boven Digoel, Provinsi Papua. Kabupaten Boven Digoel merupakan salah satu wilayah bersejarah dan merupakan daerah perbatasan di Republik Indonesia dimana daerah ini berbatasan langsung dengan negara Papua New Guinea. Secara astronomi, Kabupaten Boven Digoel terletak pada 4098' - 7010' Lintang Selatan dan 139090' - $141^{\circ}$ Bujur Timur.

Kabupaten ini berbatasan dengan Kabupaten Yahukimo dan Kabupaten Pegunungan Bintang di sebelah utara, di sebelah selatan berbatasan dengan Kabupaten Merauke, di sebelah barat berbatasan dengan Kabupaten Mappi dan di sebelah timur berbatasan dengan Negara Papua New Guinea. Jumlah hari hujan selama tahun 2018 mencapai 260 hari dengan ratarata curah hujan mencapai 403,47 mm per bulannya.

Berdasarkan demografis hasil proyeksi yang dilakukan oleh Badan Pusat Statistik, jumlah penduduk pertengahan tahun 2018 Kabupaten Boven Digoel mencapai 66.209 jiwa, dengan komposisi laki-laki sebanyak 35.673 jiwa dan perempuan sebanyak 30.536 jiwa. Berdasarkan penyebaran penduduknya, penduduk terbanyak terdapat di Distrik Jair yakni mencapai 20.650 jiwa (31,19 persen) dengan komposisi 11.636 jiwa laki-laki dan 9.014 jiwa perempuan.

Jumlah sarana pendidikan untuk tingkat SD di Kabupaten Boven Digoel pada tahun 2018 mencapai 95 sekolah, diantaranya 49 sekolah yang berstatus negeri dan 46 sekolah yang berstatus swasta. Sedangkan jumlah sarana pendidikan untuk tingkat SMP mencapai 15 sekolah, diantaranya 11 sekolah berstatus negeri dan 4 sekolah berstatus swasta. Jumlah sarana pendidikan untuk tingkat SMA/Sederajat mencapai 7 sekolah, dimana 3 sekolah merupakan sekolah kejuruan yang berstatus negeri, 2 sekolah umum berstatus negeri dan 2 sekolah umum berstatus swasta.

\section{METODE PENELITIAN}

\section{Desain Penelitian}

Desain penelitian ini adalah penelitian survey yang merupakan salah satu bentuk penelitian deskriptif, yang memaparkan apa yang terdapat atau terjadi dalam sebuah kancah, lapangan, atau wilayah tertentu. Data yang terkumpul diklasifikasikan menurut jenis, sifat, atau kondisinya. Sesudah datanya lengkap, kemudian dibuat kesimpulan (Arikunto, 2010: 3). Dengan demikian, penelitian yang dilakukan secara survey berdasarkan metode deskriptif dapat diketahui bagaimana implementasi program kartu Indonesia Sehat dalam meningkatkan kualitas Pelayanan Kesehatan di Rumah Sakit Umum Daerah Kabupaten Boven Digoel Provinsi Papua.

\section{Metode Penelitian}

Penelitian ini menggunakan metode deskriptif dengan pendekatan induktif, di mana penulis akan menggambarkan dan menganalisis mengenai bagaimana penegakan pelayanan kesehatan di Rumah Sakit Umum Daerah Kabupaten Boven Digoel Provinsi Papua. Melalui desain penelitian tersebut, peneliti berusaha mendapatkan gambaran terhadap keadaan yang sedang berlangsung pada objek penelitian sesuai dengan keadaan yang sebenarnya, sehingga dapat diperoleh data yang akurat dengan gambaran yang sebenar-benarnya dari analisis fenomena yang diteliti. 


\section{HASIL PENELITIAN DAN PEMBAHASAN}

\section{Fasilitas Pelayanan Rumah Sakit Umum Daerah Kabupaten Boven Digoel Provinsi Papua}

Sebagai rumah sakit pemerintah, Rumah Sakit Umum Daerah Kabupaten Boven Digoel ingin menuju pada pelayanan yang berkualitas dan terjangkau oleh masyarakat. Rumah Sakit Umum Daerah Kabupaten Boven Digoel dilengkapi dengan fasilitasfasilitas pelayanan. Di samping itu, Rumah Sakit Umum Daerah Boven Digoel juga mempunyai beberapa tenaga dokter spesalis, dokter umum dan dokter gigi yang akan memberi pelayanan 24 jam kepada masyarakat yang memerluka pelayanan kesehatan.

Pada pembahasan ini, peneliti menggunakan teori yang disampaikan oleh Merille S. Grindle bahwa implementasi kebijakan ditentukan oleh isi kebijakan dan konteks implementasinya. Ide dasarnya adalah setelah kebijakan ditransformasikan, barulah implementasi kebijakan hasilnya ditentukan oleh implementability.

Pelaksanaan kebijakan yang ditentukan oleh isi atau konten dan lingkungan atau konteks yang diterapkan, maka akan dapat diketahui apakah para pelaksana kebijakan dalam membuat sebuah kebijakan sesuai dengan apa yang diharapkan, juga dapat diketahui apakah suatu kebijakan dipengaruhi oleh suatu lingkungan, sehingga tingkat perubahan yang diharapkan terjadi.

Dalam penelitian ini, Implementasi Program Kartu Indonesia Sehat Dalam Meningkatkan Kualitas pelayanan Kesehatan di Rumah Sakit Umum Daerah Kabupaten Boven Digoel Provinsi Papua dapat dideskripsikan dengan model analisis kebijakan dari model Menurut Merille S. Grindle yang disebut dengan Implementation as A Political and Administration Process. Model ini terdiri dari beberapa variabel yakni:

\section{Keterkaitan Implementasi Program \\ Kartu Indonesia Sehat Dalam Meningkatkan Kualitas Pelayanan Kesehatan di Rumah Sakit Umum Daerah Kabupaten Boven Digoel}

\section{Provinsi Papua dengan Kepentingan- Kepentingan Yang Mempengaruhi}

Suatu kebijakan termasuk di antaranya adalah sebuah peraturan yang dibuat oleh pemerintah untuk menyelesaikan segala permasalahan-permasalahan di tengah masyarakat dan juga masalah di Pemerintahan dengan melibatkan kepentingan-kepentingan dari pihak tertentu ataupun pihak terkait pada tahap implementasinya. Kepentingankepentingan yang terkait oleh kebijakan tentu saja adalah sasaran dari kebijakan tersebut, seperti masyarakat dan pemerintah itu sendiri.

Kepentingan-kepentingan yang berkaitan dengan suatu Implementasi Kebijakan, indikator ini berargumen bahwa suatu kebijakan dalam pelaksanaannya pasti melibatkan banyak kepentingan, dan sejauhmana kepentingan-kepentingan tersebut membawa dampak terhadap implementasinya. Berikut ini merupakan penjelasan mengenai indikator kepentingan yang terkait dalam implementasinya.

Program Kartu Indonesia Sehat merupakan pelaksanaan dari jaminan kesehatan nasional (JKN) yang diperuntukkan bagi masyarakat miskin yang belum masuk rekapan tanggungan Jaminan Kesehatan Nasional. Kartu Indonesia Sehat dilatarbelakangi oleh dikeluarkannya Undang-Undang No.40 tentang Sistem Jaminan Sosial Nasional (SJSN). Kartu Indonesia Sehat memiliki dua pendekatan yakni kuantitas dan kualitas. Untuk pendekatan kuantitas melalui Kartu Indonesia Sehat akan ada penambahan peserta Penerima Bantuan Iuran (PBI). Dari segi kualitas, program ini mengintegrasikan layanan preventif, promotif, dan diagnosis.

Berdasarkan informasi dari wawancara, observasi dan dokumentasi, penulis dapat menginterpretasikan bahwa tidak ada kepentingan lain yang diambil oleh para pelaksana program Kartu Indonesia Sehat ini. Pegawai Rumah Sakit baik Dokter hanya melaksanakan tugasnya masing-masing untuk keberhasilan program ini. Target sasaran dari program ini adalah memberikan pelayanan kesehatan secara gratis kepada masyarakat yang kurang mampu.

Jadi dari segi isi konten implementasi kebijakan program Kartu Indonesia Sehat ini di Rumah Sakit Umum Daerah Kabupaten 
Boven Digoel ini tidak ada kepentingankepentingan dari actor penyelenggaraan semua kepentingan ini untuk masyarakat tidak mampu.

Keterkaitan Implementasi Program Kartu Indonesia Sehat Dalam Meningkatkan Kualitas Pelayanan Kesehatan di Rumah Sakit Umum Daerah Kabupaten Boven Digoel Provinsi Papua dengan Jenis Manfaat Yang diperoleh

Pada poin ini Content of Policy isi kebijakan menurut Merilee S Grindle berupaya untuk menunjukan atau menjelaskan bahwa dalam suatu kebijakan harus terdapat beberapa jenis manfaat yang menunjukan dampak positif yang dihasilkan oleh pengimplementasian kebijakan yang hendak dilaksanakan. Sebuah kebijakan yang jelas, yang memberikan manfaat yang aktual (bukan hanya formal, ritual, dan simbolis semata) kepada banyak pelaku lebih mudah di Implementasikan dibanding dengan kebijakan yang kurang bermanfaat.

Suatu kebijakan yang dibuat oleh pemerintah baik itu program, peraturan, atau perundang-undangan sebagai landasan hukumnya harus dapat memberikan hasil yang bermanfaat dan berdampak positif serta dapat merubah ke arah yang lebih baik dari hasil pengimplementasiannya. Setiap kebijakan tentunya adalah suatu upaya ataupun usaha dari pemerintah untuk menjadikan sesuatu menjadi lebih baik lagi dan dapat menyelesaikan permasalahan yang ada serta bermanfaat.

Berdasarkan informasi dari hasil wawancara, observasi dan dokumentasi, penulis dapat menginterpretasikan bahwa Pegawai Rumah Sakit sebagai pelaksana program ini tidak memperoleh manfaat apapun, mereka hanya sebagai implementor dari program ini. Beda halnya dengan Peserta Kartu Indonesia Sehat yang menjadi target dari program ini, mereka yang merupakan masyarakat yang kurang mampu dengan kondisi ekonominya yang sangat lemah, dapat memperoleh pelayanan kesehatan secara gratis. Selain itu, Kartu Indonesia Sehat digunakan tidak hanya untuk pengobatan saja, tetapi juga dapat digunakan untuk pencegahan berupa dilakukannya konsultasi mengenai kesehatan.
Jadi dari segi isi konten implementasi kebijakan program Kartu Indonesia Sehat di Rumah Sakit Umum Daerah Kabupaten Boven Digoel Provinsi Papua ini tidak ada manfaat yang di ambil dari actor penyelenggaraan pelayanan kesehatan semua manfaat ini untuk masyarakat tidak mampu.

Keterkaitan Implementasi Program Kartu Indonesia Sehat Dalam Meningkatkan Kualitas Pelayanan Kesehatan di Rumah Sakit Umum Daerah Kabupaten Boven Digoel Provinsi Papua dengan Derajat Perubahan Yan Ingin Dicapai

Dalam suatu kebijakan tidak dapat dipisahkan dari adanya suatu target yang ingin dicapai. Adapun yang ingin dijelaskan pada poin ini adalah seberapa besar perubahan yang ingin dicapai melalui suatu Implementasi Kebijakan harus mempunyai skala yang jelas. Sebuah kebijakan diharapkan dapat memberikan manfaat yang baik secara berkelanjutan. Suatu implementasi yang baik akan memberikan output yang baik untuk jangka waktu yang singkat maupun waktu yang panjang secara terus menerus serta teratur.

Berdasarkan observasi dan dokumentasi yang dilakukan, penulis melihat fasilitas yang ada di Rumah tidak dipergunakan secara maksimal. Dalam beberapa hari peneliti mengamati ruang rawat inap, bahwa tidak ada satu pasien pun yang dirawat, padahal jika ruang rawat inap tersebut dimanfaatkan dengan baik, tentu dapat mengatasi membludaknya pasien yang ada di rumah sakit rujukan.

Berdasarkan informasi di atas, terkait perubahan yang diharapkan peneliti dapat menginterpretasikan bahwa Pegawai Rumah Sakit sebagai pelaksana program ini menginginkan peserta Kartu Indonesia Sehat merasa puas atas pelayanan yang mereka terima serta lebih memahami bagaimana pola hidup sehat agar tidak mudah sakit. Kemudian perubahan yang diharapkan oleh Peserta Kartu Indonesia Sehat terkait pelaksanaan program ini adalah adanya perbaikan pelayanan yang mereka terima baik itu dari perilaku pegawai maupun kelengkapan sarana dan prasarana, serta memaksimalkan pengunaan fasiltas yang telah ada di Rumah Sakit. 
Jadi dari segi isi konten implementasi kebijakan program Kartu Indonesia Sehat di Rumah Sakit Umum Daerah Kabupaten Boven Digoel Provinsi Papua ini adalah ingin mengangkat deraja perrubahan yang ingin dicapai oleh masyarakat terutama derajat pelayanan kesehata yang baik.

\section{Faktor Pendukung dan Faktor Penghambat Implementasi Program Kartu Indonesia Sehat Dalam Meningkatkan Kualiats Pelayanan Kesehatan di Rumah Sakit Umum Daerah Kabupaten Boven Digoel Provinsi Papua}

Dari hasil observasi yang di lakukan oleh peneliti di lapangan menujukan bahwa masih minimnya sarana dan prasarana yang membuat pelayanan kesehatan di Rumah Sakit Umum Daerah Kabupaten Boven Digoel Provinsi Papua ini belum berjalan secara optimal.

Berdasarakan informasi dan hasil observasi wawancara dan dukumentasi di lapangan penelitian di Rumah Sakit Umum Daerah Boven Digoel Provinsi Papua dari segi pedukung Sumber Daya Manusia sudah cukup baik tetapi dari segi penghambat masih minimnya sarana dan prasana yang belum memadai di Rumah Sakit Umum Daerah Boven Digoel Provinsi Papua ini yang membuat pelayanan program Kartu Indonesia Sehat dari pemerintah ini belum dapat terealisasi dengan baik di Rumah Sakit Umum Daerah Kabupaten Boven Digoel Provinsi Papua.

Peneliti juga melakukan dokumentasi di lapangan, di rumah sakit dari segi pedukung Sumber Daya Manusia atau medis sudah cukup baik sendangkan faktor penghambat jalannya program Kartu Indonesia Sehat dari pemerintah ini masih minimnya pos anggaran yang belum berjalan dengan baik hingga program Kartu Indonesia Sehat dari pemerintah ini belum benar-benar di sosialisaikan kepada masyarakat di Rumah Sakit Umum Daerah Kabupaten Boven Digoel Provinsi Papua.

Strategi Dalam Mengatasi Penghambat Implementasi Program Kartu Indonesia Sehat Dalam Meningkatkan Kualiats Pelayanan Kesehatan di Rumah Sakit

\section{Umum Daerah Kabupaten Boven Digoel Provinsi Papua}

Penelitian mengenai Implementasi Program Kartu Indonesia Sehat dalam Meningkatkan Kualitas Pelayanan Kesehatan di Rumah Sakit Umum Daerah Kabupaten Boven Digoel Provinsi Papua, dengan melihat berbagai faktor maka peneliti dapat merumuskan beberapa strategi yang dapat diterapkan oleh Direktur Rumah Sakit dan pemerintah Kabupaten Boven Digoel Provinsi Papua agar pelaksanaan implementasi dapat berjalan secara efektif dalam meningkatkan kualitas pelayanan kesehatan di rumah sakit.

Untuk menghasilkan strategi yang tepat maka akan di gunakan analisis SWOT dengan mengidentifikasikan faktor-faktor seperti Strengh (kekuatan), Weaknees (kelemahan), Opportunities (peluang), dan Threaths (ancaman). Berdasarkan hasil matriks (SWOT) dan tabel Indikator Kekuatan, kelemahan, peluang, dan ancaman tersebut dengan pemetaan interaksi faktor-faktor eksternal dan internal dihasilkan sejumlah isu strategis dalam Implementasi Program Kartu Indonesia Sehat dalam Meningkatkan Kualitas Pelayanan Kesehatan di Rumah Sakit Umum Daerah Kabupaten Boven Digoel Provinsi Papua, adapun isu strategis itu antara lain:

1) Strategi S-O Strategi ini bersumber dari Strenghtsdan Opportunities. Strategi S$\mathrm{O}$ ini diciptakan dengan menggunakan kekuatan untuk memanfaatkan peluang yang ada. Strategi yang harus diterapkan dalam kondisi ini adalah mendukung kebijakan pertumbuhan yang agresif / growth oriented strategy. Strategi S-O yang diambil adalah pelayanan kesehatan. Untuk itu strategi S-T yang diambil adalah Memanfaatkan teknologi informasi dan iklan dalam memperkenalkan program-program pemerintahan baik program Kartu Indonesia Sehat di Rumah Sakit Umum Daerah Kabupaten Boven Digoel Provinsi Papua ini. 2) Strategi W-O Srategi yang bersumber dari Weakness dan Opportunitiesini merupakan sebuah strategi yang diciptakan dengan meminimalkan kelemahan untuk memanfaatkan peluang. Mendukung strategi turnaraound (putar balik), dalam artian mengambil beberapa 
langkah untuk mengatasi berbagai kelemahan yang dihadapi secara internal agar peluang dapat dimanfaatkan. Strategi W-O yang diambil adalah Kerjasama yang baik antara Pememerintah Daerah, Dinas kesehatan, dan Rumah Sakit dalam meningkatkan Program-Program pemerintahan baik Program Kartu Indonesia Sehat ini kepada masyarakat di Kabupaten Boven Digoel Provinsi Papua.

3) Strategi S-T Strategi yang bersumber dari Strenghts dan Threts ini merupakan strategi yang diciptakan dengan menggunakan kekuatan dari lingkungan internal untuk mengatasi ancaman yang berasal dari lingkungan eksternal. Meskipun menghadapi ancaman, organisasi masih memiliki kekuatan secara internal. Strategi yang harus diterapkan adalah menggunakan kekuatan untuk memanfaatkan peluang jangka panjang dengan cara diversifikasi. Dalam pengembangan pelayanan kesehatan di Kabupaten Boven Digoel Provinsi Papua ini, strategi S-T yang diambil adalah Sosialisasi program Kartu Indonesia Sehat dari tim Rumah Sakit kepada masyarakat Secara Rutin di Rumah Sakit Umum Daerah Kabupaten Boven Digoel Provinsi Papua. Di dalam penembangan pelayanan kesehatan kita membutuhkan peran serta kualitas untuk ikut serta mengembangkan layanan kesehatan. Faktor penyandang dana sangat penting untuk dikenali sebagai faktor eksternal yang dekat sebab dampaknya bersifat langsung.

4) Strategi W-T Strategi yang bersumber dari Weakness dan Threatsini merupakan sebuah strategi yang diciptakan dengan meminimalkan kelemahan dan menghindari ancaman. Kelemahan yang bersumber dari lingkungan internal kemudian diminimalisir dan juga digunakan untuk menghindari ancaman dari lingkungan eksternal. Ini merupakan kondisi yang sangat tidak menguntungkan, organisasi mengalami berbagai ancaman dan kelemahan internal. Strategi yang mendukung adalah strategi defensif yaitu dengan melakukan berbagai tindakan yang sifatnya inovatif. Strategi yang diambil adalah Meningkatkan sarana dan prasarana yang mampu menujang kualitas pelayanan kesehatan di Rumah Sakikt Umum
Daerah Kabupaten Boven Digoel Provinsi Papua.

\section{Perumusan Isu Strategi Implementasi Program Kartu Indonesia Sehat Dalam Meningkatkan Kualiats Pelayanan Kesehatan di Rumah Sakit Umum Daerah Kabupaten Boven Digoel Provinsi Papua.}

Dari ke empat isu strategi di atas, kemudian tahapan selanjutnya yaitu merumuskan program-program strategi pemerintah tentang program Kartu Indonesia Sehat di Rumah Sakit Umum Daerak Kabupaten Boven Digoel Provinsi Papua. Dalam perumusan program-program strategi ini, diperlukan kerjasama yang baik antara Pemerintah Daerah, Dinas Kesehatan, dan Rumah Sakit. Berikut adalah rincian perumusan program-program strateginya:

1. Memanfaatkan teknologi informasi dan iklan dalam memperkenalkan program Kartu Indonesia Sehat di Rumah Sakit Umum Daerah Kabupaten Boven Digoel Provinsi Papua:

a. Menciptakan iklan pelayanan kesehatan dan informasi yang akurat mengenai pelayanan kesehatan yang baik di Rumah Sakit Umum Daerah Kabupaten Boven Digoel Provinsi Papua.

b. Ruang informasi yang benar-benar berperang aktif dalam memperkenalkan sumber daya medis dan juga memperkenalkan fasilitas sarana dan prasarana yang ada di Rumah Sakit Umum Daerah Kabupaten Boven Digoel Provinsi Papua.

c. Belum ada iklan atau informasi yang menawarkan pelayanan publik dari pemerintah pusat kepada masyarakat yang tidak mampu pemerintah daerah belum mampu untuk memberikan infomasi kepada masyarakat hingga masih banyak masyarakat belum mengetahui program pemerintah ini.

2. Meningkatkan sarana dan prasarana yang mampu menujang kualitas pelayanan kesehatan di Rumah Sakikt 
Umum Daerah Kabupaten Boven Digoel Provinsi Papua:

a. Masih minimya fasilitas sarana pelayanan medis yang benar-benar bisa menujang proses pelayanan kesehatan di Rumah Sakit Umum Daerah Kabupaten Boven Digoel Provinsi Papua.

b. Masih kurangnya fasilitas prasarana yang baik misalnya ruang rawat inap, ruang tunggu pasien, tempat duduk pasien untuk pengambilan obat-obatan yang masih minim.

c. Masih kurangnya kerja sama yang baik dari pihak pemerintah daerah, Dinas kesehatan, dan Rumah Sakit, dalam menyediakan fasilitas pelayanan kesehatan yang menujang program-program Pemerintah pusat baik itu seperti program Kartu Indonesia Sehat yang ada sekarang.

d. Dengan adanya fasilitas sarana dan prasarana ini bisa dapat meningkatkan kualitas pelayanan kesehatan yang baik kepada masyarakat.

3. Kerjasama yang baik antara Pemerintah Daerah, Dinas kesehatan, dan Rumah Sakit Umum Daerah Kabupaten Boven Digoel dalam memperkenalkan Program Kartu Indonesia Sehat:

a. Adanya kerja sama yang baik dari pemerintah Daerah Dinas kesehatan, Rumah Sakit untuk meningkatkan program Kartu Indonesia Sehat ini kepada masyarakat.

b. Adanya peran aktif dari pemerintah daerah untuk menyediakan anggara untuk mejalankan program Kartu Indonesia Sehat ini.

c. Program Kartu Indonesia Sehat ini belum dapat berjalan dengan baik karena masih minimnya kerja sama yang baik dari pemerintah daerah, Danis kesehatan, dan Rumah Sakit Umum Daerah di Kabupaten Boven Digoel Provinsi Papua ini.

4. Sosialisasi Program Kartu Indonesia Sehat dari tim Rumah Sakit kepada masyarakat Secara Rutin di Rumah Sakit Umum Daerah Kabupaten Boven Digoel Provinsi Papua: a. Peran Pemerintah Daerah dalam mesosialisasikan program Kartu Indonesia Sehat Kepada masyarakat.

b. Kerja sama yang baik dari Pemerintah Daerah, Dinas kesehatan, dan Rumah Sakit Umum Daerah dalam mesosialisaikan program pemerintah yang baik ini kepada semua warga di Kabupaten Boven Digoel Provinsi Papua.

c. Banyak masyarakat yang belum memahami tentang cara mengurus Kartu Indonesia Sehat ini karena belum adanya sosialisai yang baik dari Dinas kesehatan, dan pihak Rumah Sakit.

\section{KESIMPULAN}

Dari pembahasan tersebut, peneliti menyimpulkan beberapa hal berikut ini:

a. Implementasi Program Kartu Indonesia Sehat dari segi sisi content of polcy kebijakan implementasi belum terlaksana dengan optimal, sehingga Rumah Sakit Umum Daerah di Kabupaten Boven Digeol Provinsi Papua tidak dapat berjalan secarah utuh.

b. Implementasi Program Kartu Indonesia Sehat dari segi sisi context of polcy Pelaksanaan dari suatu kebijakan implementasi tidak akan lepas terpengaruhi dari kekuasaan, kepentingan dan juga strategi yang dilakukan oleh para aktor.

c. Faktor pendukung:

1) Kalau di lihat dari ijin Rumah Sakit Umum Daerah Boven Digoel Provinsi Papua di beri Ijin Operasional No. 5 tanggal 13 Februari 2012 serta diperpanjang Ijin Operasionalnya pada tanggal 20 Agustus Tahun 2018 sampai dengan Agustus Tahun 2023.

2) Rumah Sakit Umum Daerah Kabupaten Boven Digoel Provinsi Papua adalah Rumah Sakit Tipe D yang di milik oleh Pemerintah Daerah Kabupaten Boven Digoel Provinsi Papua.

3) Kalau dilihat dari sisi 
sumberdaya medis baik dokter, bidan, apokteker, sudah cukup memadai di Rumah Sakit Umum Daerah Kabupaten Boven Digoel Provinsi Papua.

d. Faktor penghambat:

1) Belum adanya peran pemerintah daerah dalam menyediakan fasilitas sarana dan prasarana medis di Rumah Sakit Umum Daerah Kabupaten Boven Digoel Provinsi Papua.

2) Jarak jauh perumahan masyarakat dan Rumah Sakit Umum Daerah Kabupaten Boven Digoel Provinsi Papua.

3) Belum adanya peran media teknologi infomasi dan iklan dalam memperkenalkan program Kartu Indonesia Sehat di Rumah Sakit Umum Daerah Kabupaten Boven Digoel Provinsi Papua.

e. Strategi apa saja yang perlu dapat dilakukan guna untuk mengatasi hambatan-hambatan Implementasi Program Kartu Indonesia Sehat:

1) Memanfaatkan teknologi informasi dan iklan dalam memperkenalkan program Kartu Indonesia Sehat di Rumah Sakit Umum Daerah Kabupaten Boven Digoel Provinsi Papua.

2) Menyediakan sarana dan prasarana yang memadai di Rumah Sakikt Umum Daerah Kabupaten Boven Digoel Provinsi Papua.

3) Kerjasama yang baik antara Pememerintah Daerah, Dinas kesehatan, dan Rumah Sakit Umum Daerah Kabupaten Boven Digoel Provinsi Papua dalam memperkenalkan Program Kartu IndonesiaSehat.

\section{DAFTAR PUSTAKA}

Alam Et Al. 2012. Solid-Acid And IonicLiquid Catalyzed One-Pot Transformation Of Biorenewable Substrates Into A Plantform Chemical And A Promising Biofuel. Rsc
Advances: Rcc Adv., 2012, 2, 68906896/6891.

Albert, Kurniawan. 2010. Belajar Mudah SPSS Untuk Pemula. Yogyakarta: Mediakom.

Aneta, Asna. 2010. Implementasi Kebijakan Program Penanggulangan Kemiskinan Perkotaan (P2KP) Kota Gorontalo. Jurnal Administrasi Publik.

Arikunto, S. 2006. Prosedur Penelitian: Suatu Pendekatan Praktik. Jakarta: Rineka Cipta.

Bintoron, Tjokroamidjojo. 1978. Pengantar Administrasi Pembangunan.Jakarta: LP3ES.

Bruce, A, Et Al. 1989. Molecular Biology Of The Cell, Second Edition. Garland Science. New York.

Budiman, Dan Riyanto Agus. 2013. Pengetahuan Dan Sikap Dalam Penelitian Kesehatan. Jakarta: Salemba Medika.

Creswell, John W. 2015. Penelitian Kualitatif dan Desain Riset: Memilih Diantara Lima Pendekatan. Yogyakarta: Pustaka Pelajar

Chen And Lin. 2013. Applying Importance Peformance Analysis For Improving Internal Marketing Of Hospital Management In Taian. Jornalinternational Business Research. Vol 6 No. 4 Hal, 45-54.

Indiahono, Dwiyanto. 2009. Kebijakan Publik: Berbasis Dynamic Policy Analysis. Yogyakarta: Gava Media.

Kotler, Philip, 2000, Marketing Management. Edisi Milenium, Prentice Hall Int, Inc New Jersey.

Kalalo, Dkk. 2017. Implementasi Kebijakan Publik Pembuatan E-Ktp Tahun 2016 Di Dinas Pencatatan Sipil Kabupaten Minahasa. Jurnal Eksekutif, Vol 1 No 1.

Kemenkes RI. Profil Kesehatan Indonesia tahun 2014. Jakarta: Kemenkes RI; 2015.

Kriyantono, Rachmat. 2012. Teknik Praktis Riset Komunikasi. Jakarta: Kencana.

Maharani \&Amp; Santosa, 2015. Perbandingan Pengetahuan Infeksi Nosokomial Pada Tenaga Kerja Medis Dan Non Medis Di Rumah Sakit (Studi Analitik Di Rumah Sakit Bhakti Asih Brebes). Jurnal Media Medika Muda Vol. 4, No. 2, Hal:67-78. 
Mulyasa. 2013. Pengembangan Dan Implementasi Kurikulum 2013. Bandung: Pt Remaja Rosadakarya.

Manullang.1987. Dasar-Dasar Manjemen. Jakarta: Ghalia Indonesia. Meter, Donald Van, dan Carl Van Horn, 1975, "The Policy Implementation Process: A Conceptual In Administration And Society 6, 1975, London: Sage

Nugroho, Rian. 2009. Public Policy. Jakarta: Elek Media Komputindo.

Panggabean, Samsul Rizal. 2008. Kemajemukan Internal Dan Masalah Stateness" Dalam Hamid Basyaib (Peny.), Dari Colombus Untuk Indonesia: 70 Tahun Profesor Bill Liddle Dari Murid Dan Sahabat. Jakrta: Kpg.

Parasuraman, A., Zeithaml, Va., Berry, L.L. 1990, Delevering Quality Service :Balancing Customer Perception And Expectations, The Free Press :London.

Ratminto \& Winarsih, Atik Septi, 2005. Manajemen

Pelayanan: Pengembanganmodel Konseptual, Penerapan Citizen's Charter Dan Standarpelayanan Minimal, Pustaka Pelajar; Yogyakarta.

Rangkuti, 2004, Analisis SWOT Teknik Membedah Kasus Bisnis, PT. Graedia, Jakarta.

Sedarmayanti. 2014. Manajemen Sumber Daya Manusia Reformasi Birokrasi dan Manajemen Pegawai Negeri Sipil. Bandung: PT. Refika Aditama

Samin, Rumzi. 2011. Reformsi Birokrasi. Jurnal Fisip Umrah. Vol, 2 No.2 Hal, $172-182$.

Sugiyono, 2007. Metode Penelitian Kuantitatif Kualitatif Dan R\&D. Bandung: Alfabeta.

Sukendro, 2009. Basic Hospital Public Relationship: Dasar-Dasar Humas Rumah Sakit. Yogyakarta: Amara Books.

Vandawati, Dkk. 2016. Aspek Hukum Kartu Indonesia Sehat. Yuridika: Volume 31 No 3, September-Desember 2016.

Wahab, Solichin Abdul. 2014. Analisis Kebijakan: Dari Formulasi $\mathrm{Ke}$ Penyusunan Model-Model Implementasi Publik. Jakarta: Bumi Aksara.
Wahyuni, Dwi Sari. 2013. Implementasi Peraturan Daerah Nomor 12 Tahun 2002 Tentang Rencana Tata Ruang Kota Samarinda. Ejournal Administrasi Negara, 2013, 1 (1): 109-12.

Winarno, Budi. 2012. Kebijakan Publik (Teori, Proses, Dan Studi Kasus). Yogyakarta: Caps. 